Surgery for

Congenital

Heart Disease

\title{
New approach to multiple ventricular septal defect closure with intraoperative echocardiography and double patches sandwiching the septum
}

Christian P. Brizard, MD

Christian Olsson, $\mathrm{MD}^{\mathrm{b}}$

James L. Wilkinson, MB, FRACPa
From the Cardiac Surgery Unit and Department of Cardiology, Royal Children's Hospital, Melbourne, Australia, ${ }^{a}$ and Thoraxkirurgiska kliniken, Akademiska sjukhuset, Uppsala, Sweden. ${ }^{\mathrm{b}}$

Read at the Eighty-third Annual Meeting of The American Association for Thoracic Surgery, Boston, Mass, May 4-7, 2003.

Received for publication May 5, 2003; revisions received April 30, 2004; accepted for publication May 7, 2004.

Address for reprints: Christian Brizard, MD, Director, Cardiac Surgery Unit, Royal Children's Hospital, Parkville 3052, Victoria, Australia (E-mail: cardiac.surgery@ rch. org.au).

J Thorac Cardiovasc Surg 2004;128:684-92 $0022-5223 / \$ 30.00$

Copyright (c) 2004 by The American Association for Thoracic Surgery

doi:10.1016/j.jtcvs.2004.05.018
Objective: This was an evaluation of a new approach to the management of multiple muscular ventricular septal defects. The defects were located with epicardial echocardiography, then transfixed with a guide wire inserted directly through the right ventricular free wall. They were closed with a custom-made multilayered doublepatch device under cardioplegic arrest through a standard right atriotomy.

Methods: This was a retrospective study of 14 consecutive patients.

Results: The median age and body weight at repair were 40 days (range 1 week-8 years, 3 months) and $4.1 \mathrm{~kg}(2.8-24 \mathrm{~kg})$, respectively. Five patients $(36 \%)$ had undergone at least one previous sternotomy; 11 patients (78\%) had associated cardiac lesions. Closure of the multiple septal defects was successful in 12 patients $(85 \%)$. Failure to localize all defects led to pulmonary artery banding in 2 patients. One patient had the residual septal defect closed with a percutaneous device 6 months later, and in the second patient the residual defect was closed with a conventional approach 11 months afterward. Two patients had permanent pacemaker insertion. In 279 patient-months of follow-up, there was 1 cardiac arrest on day 1 and no early or late deaths; all children but one are free of cardiac medications, and no significant residual left-to-right shunts were demonstrated in any patient.

Conclusion: The reported management of multiple ventricular septal defects has been successful in this series, even in neonates and infants with complex associated cardiac lesions. It appears safe, simple, and effective.

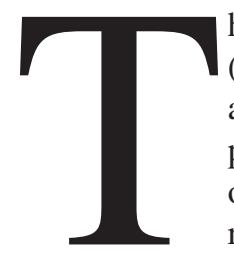

he management of patients with multiple ventricular septal defects (VSDs) remains a surgical challenge, with primary surgical repair to avoid palliation increasingly favored. ${ }^{1-3}$ In the neonate and infant, primary repair can be demanding. The intraoperative identification of muscular defects is difficult through the right atriotomy. Often this requires long aortic crossclamp and cardiopulmonary bypass (CPB) times and right or left ventriculotomies. Left ventriculotomies have long-term complications. ${ }^{4,5}$ Eventually some VSDs may never be found, despite extensive resection of muscular trabeculations, and may generate large residual shunts. Alternately, the initial palliation with pulmonary artery banding has inherent morbidity 
TABLE 1. Surgical characteristics of the 14 patients undergoing closure of multiple VSDs

\begin{tabular}{|c|c|c|c|c|c|}
\hline Case & $\begin{array}{l}\text { Associated } \\
\text { lesions }\end{array}$ & Previous interventions & $\begin{array}{l}\text { Age at } \\
\text { repair }\end{array}$ & Surgical procedures & $\begin{array}{l}\text { Discharge transthoracic } \\
\text { echocardiographic findings }\end{array}$ \\
\hline 1 & Coarctation & $\begin{array}{l}\text { (1) Coarctation repair plus } \\
\text { PAB; (2) PA debanding, } \\
\text { patch closure of one VSD }\end{array}$ & $4 \mathrm{y}, 7 \mathrm{mo}$ & $\begin{array}{l}\text { Closure of midmuscular VSD } \\
\text { (device), apical VSD (device); } \\
\text { apical ventriculotomy }\end{array}$ & $\begin{array}{l}\text { Remaining apical VSD; no } \\
\text { significant shunt; progressive } \\
\text { severe dilated cardiomyopathy }\end{array}$ \\
\hline 2 & None & $\begin{array}{l}\text { (1) PDA ligation plus PAB; } \\
\text { (2) Exploration after } \\
\text { cardiac perforation in } \\
\text { catheter lab }\end{array}$ & $8 \mathrm{y}, 3 \mathrm{mo}$ & $\begin{array}{l}\text { Closure of perimembranous } \\
\text { VSD (suture), apical VSD } \\
\text { (device); apical } \\
\text { ventriculotomy }\end{array}$ & $\begin{array}{l}\text { Two minimal residual shunts; good } \\
\text { LV function }\end{array}$ \\
\hline 3 & AVSD & $\begin{array}{l}\text { (1) PAB; (2) AVSD repair } \\
\text { plus PA debanding }\end{array}$ & $2 y$ & $\begin{array}{l}\text { Closure of midmuscular VSD } \\
\text { (device); trivial apical VSD } \\
\text { not approached }\end{array}$ & $\begin{array}{l}\text { Small apical VSD; no shunt over } \\
\text { patch; good LV function }\end{array}$ \\
\hline 4 & TGA & BAS & $7 d$ & $\begin{array}{l}\text { ASO plus closure of } \\
\text { midmuscular VSD (suture) } \\
\text { plus closure of midmuscular } \\
\text { VSD (device) }\end{array}$ & $\begin{array}{l}\text { Minimal shunt over remaining } \\
\text { muscular VSD; good LV function }\end{array}$ \\
\hline 5 & TGA, LVOTO & BAS & $9 d$ & $\begin{array}{l}\text { ASO plus LVOTO resection plus } \\
\text { PAB; midmuscular VSD could } \\
\text { not be localized }\end{array}$ & $\begin{array}{l}\text { Two small muscular VSDs, } \\
\text { bidirectional shunt; after VSD } \\
\text { closure with Amplatzer device, } \\
\text { no shunt and good LV function }\end{array}$ \\
\hline 6 & TGA & BAS & $1 \mathrm{mo}$ & $\begin{array}{l}\text { ASO plus closure of high } \\
\text { muscular VSD (device) }\end{array}$ & $\begin{array}{l}\text { Remaining small apical VSD; no } \\
\text { shunt over addressed VSD; good } \\
\text { LV function }\end{array}$ \\
\hline 7 & None & PAB & $6 \mathrm{y}, 1 \mathrm{mo}$ & $\begin{array}{l}\text { Closure of } 3 \text { trabecular VSDs } \\
\text { (apical, } 3 \text { devices); apical } \\
\text { ventriculotomy; } 2 \text { separate } \\
\text { crossclamps }\end{array}$ & No shunt; good LV function \\
\hline 8 & Coarctation & Coarctation repair plus $\mathrm{PAB}$ & $1 \mathrm{y}, 4 \mathrm{mo}$ & $\begin{array}{l}\text { Closure of apical VSD } \\
\text { ( } 2 \text { devices) plus PA } \\
\text { debanding }\end{array}$ & $\begin{array}{l}\text { Small residual apical VSD (velocity } \\
3.6 \mathrm{~m} / \mathrm{s} \text { ); good LV function }\end{array}$ \\
\hline 9 & $\begin{array}{l}\text { Truncus } \\
\text { arteriosus }\end{array}$ & & $29 d$ & $\begin{array}{l}\text { Truncus repair (12-mm } \\
\text { homograft); apical VSD } \\
\text { (device); subarterial VSD } \\
\text { patch }\end{array}$ & $\begin{array}{l}\text { Angiography pulmonary/systemic } \\
\text { perfusion ratio } 1: 1\end{array}$ \\
\hline 10 & $\begin{array}{l}\text { DORV, } \\
\text { LVOTO }\end{array}$ & PAB & $42 \mathrm{~d}$ & $\begin{array}{l}\text { DORV repair; SAS resection; } \\
\text { closure perimembranous } \\
\text { VSD (patch); closure high } \\
\text { anterior trabecular VSD } \\
\text { (device) }\end{array}$ & $\begin{array}{l}\text { No residual shunt; good LV } \\
\text { function }\end{array}$ \\
\hline 11 & TGA & & $60 \mathrm{~d}$ & $\begin{array}{l}\text { ASO; } 2 \text { muscular VSDs closed } \\
\text { (devices); } 1 \text { muscular VSD } \\
\text { left (banded) }\end{array}$ & $\begin{array}{l}\text { Good LV function; no shunt at } 4 \\
\text { mo }\end{array}$ \\
\hline 12 & TGA & & $11 \mathrm{~d}$ & $\begin{array}{l}\text { ASO; perimembranous VSD } \\
\text { patch; muscular VSD device } \\
\text { ( } 2 \text { crossclamps) }\end{array}$ & No shunt; good LV function \\
\hline 13 & Coarctation & Coarctation repair & $38 \mathrm{~d}$ & $\begin{array}{l}\text { Inlet VSD patch, anterior } \\
\text { muscular device }\end{array}$ & Trivial shunt; good LV function \\
\hline 14 & $\begin{array}{l}\text { Hypoplastic } \\
\text { arch }\end{array}$ & Extended arch repair & $26 \mathrm{~d}$ & $\begin{array}{l}2 \text { midmuscular VSDs (2 } \\
\text { devices, } 2 \text { crossclamps); } \\
\text { apical VSD direct suture; } \\
\text { apical ventriculotomy; } \\
\text { cardiac arrest } 18 \mathrm{~h} ; \text { ECMO }\end{array}$ & $\begin{array}{l}\text { Trivial shunt; good LV function; } \\
\text { bronchomalacia }\end{array}$ \\
\hline
\end{tabular}

$\overline{P A B}$, Pulmonary artery banding; $P A$, pulmonary artery; $P D A$, patent ductus arteriosus; $A V S D$, atrioventricular septal defect; TGA, transposition of the great arteries; $B A S$, balloon atrioseptostomy; $A S O$, arterial switch operation; LVOTO, LV outflow tract obstruction; DORV, double-outlet RV; ECMO, extracorporeal membrane oxygenation; $S A S$, subaortic stenosis. 


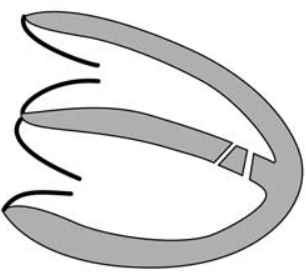

1

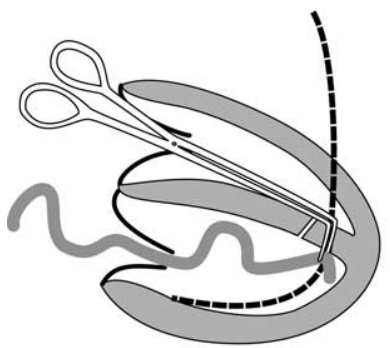

3

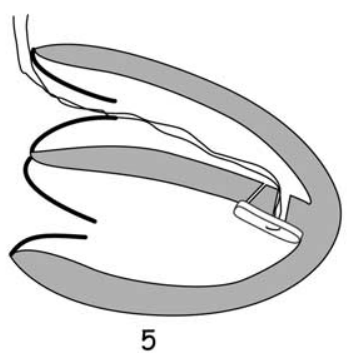

Figure 1. Schematic step-by-step implantation of device.

and significant technical drawbacks in the presence of major associated cardiac defects. Other alternatives include catheter-delivered VSD devices. The VSDs need to match strict anatomic exclusions criteria, however, and the delivery system is unsafe in neonates and young infants.

We report a technique in which the difficulties of the management of multiple VSDs are addressed: intraoperative recognition of the VSDs, direct location of the VSDs, and simple and effective closure without left ventriculotomies. The technique is described, together with follow-up data.

\section{Patients and Methods}

\section{Patients}

Fourteen consecutive children were operated on during a 36-month period from February 2000 to February 2003. The indication was multiple muscular VSDs, regardless of the presence of other cardiac defects. All parents gave written, informed preoperative consent. Median age at final repair was 40 days (range 1 week-8 years), and median body weight was $4.1 \mathrm{~kg}(2.8-23.9 \mathrm{~kg})$. Five patients $(36 \%)$ had a previous sternotomy with placement of a pulmonary artery band or other procedures (Table 1). Eleven

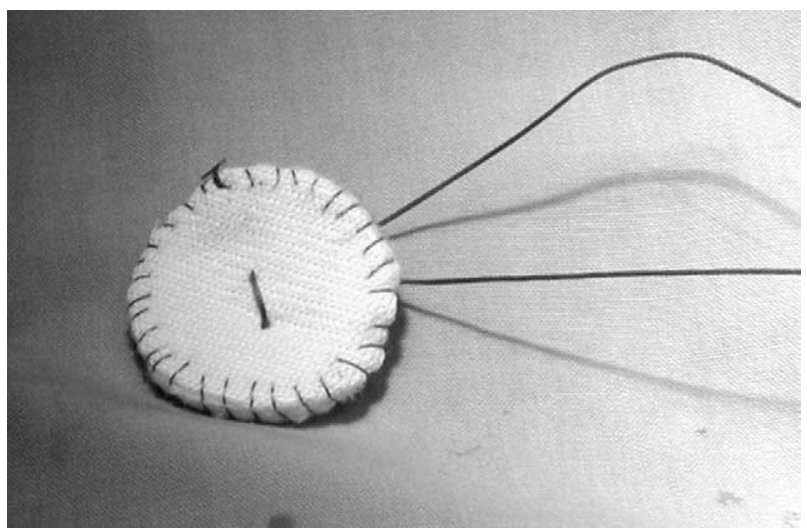

Figure 2. Custom-made patch with the braided mattress suture inserted. There are two layers: woven Dacron polyester fabric on cameral aspect of patch and thick, soft PTFE felt on endocardial aspect.

patients had associated cardiac defects (78.5\%). In 3 patients a coarctation had been previously repaired through a left thoracotomy; 1 underwent banding simultaneously.

\section{Intraoperative VSD Recognition, Pinpointing, and Closure (Figure 1)}

Before the operation, circular composite patches of various diameters, with an outer layer of knitted polytetrafluoroethylene (PTFE, Bard Edwards Outflow Tract Fabric; IMPRA, Tempe, Ariz) and an inner layer of thick, soft PTFE felt (Bard PTFE Felt; IMPRA) were prepared. The two components were sutured together circumferentially and sterilized. The final appearance of the patch is illustrated in Figure 2. During the operation, the diameter of the chosen patches was according to the echocardiographic measurements and the number of VSDs to cover.

Under moderate hypothermic $\left(34^{\circ} \mathrm{C}\right) \mathrm{CPB}$ and some volume loading to gently distend the heart and the septum, an epicardial echocardiographic study (Agilent Sonos 5500 with 12-MHz S12 probe; Forest Hill, Victoria, Australia) was performed to localize the VSDs. Once identified, the largest or most central muscular VSD channel was traversed directly through the right ventricular (RV) free wall (Figure 3). In the 9 nine cases, a flexible guide wire was used (0.018 inch in diameter, $40 \mathrm{~cm}$ long; Cook Group Incorporated, Bloomington, Ind), whereas in the first 5 patients in the series, a 3F Fogarty catheter was used (Applied Medical, Laguna Hills, Calif). The inflated balloon of the catheter secured the position in the left ventricle (LV). Guide wires were sutured in position on the RV. If remaining VSDs were remote, they were addressed in a similar fashion. If the VSD could not be traversed, the guide wire was secured in a position exactly at the RV ostium of the VSD. Once the VSDs were pinpointed, the heart was drained, the temperature was lowered $\left(32^{\circ} \mathrm{C}\right)$, and the aorta was crossclamped. Antegrade cold blood cardioplegia was used. The guide wire in the RV was seen through the tricuspid valve, demonstrating the main muscular VSD. Then a right-angled instrument was introduced into the VSD from the RV side. The tip could be seen in the LV through a perimembranous VSD (if present), through the mitral valve, or through the transected main pulmonary 


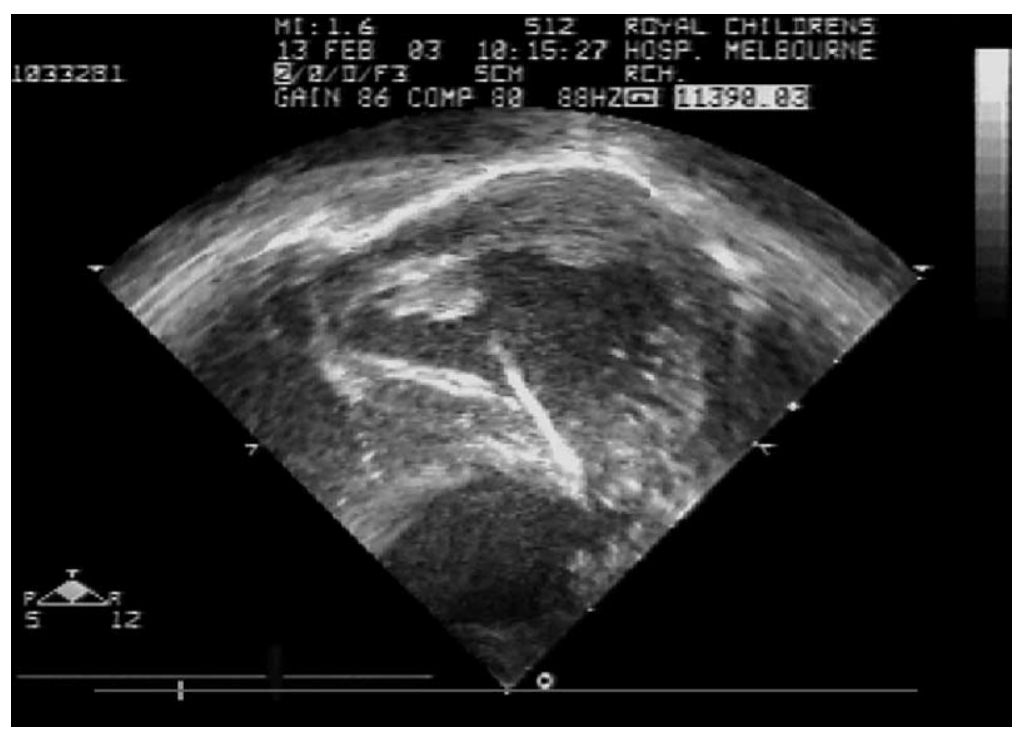

Figure 3. Epicardial intraoperative echocardiographic study in patient with transposition of great arteries before repair demonstrates anterior muscular VSD; VSD is transfixed with guide wire.

artery, depending on the approach to coexisting defects. A silicone tape, secured to a 2-0 (or 3-0) mattress suture mounted onto the prepared patch, was grasped and pulled back into the RV, seating the patch snugly to the LV side of the septum. The sutures were threaded through an identical patch. The second patch was tied down to the RV aspect of the septum, thus sandwiching the VSDs. This could be done either through the tricuspid valve or, with apical VSDs, through a small, purpose-made RV incision. When several VSDs were in close relation, they were collectively closed with oversized patches. For distant VSDs, to avoid very large patches and plastering of the septum, separate double patches were used. Coexisting cardiac lesions were addressed. After CPB, the VSD closure was assessed with epicardial echocardiography to detect a residual left-to-right shunt, and simultaneous blood samples were taken from the right atrium and pulmonary artery to calculate the magnitude of such a shunt.

After the operation, all patients had at least one transthoracic echocardiographic study performed before discharge. Continued follow-up and medical management were at the discretion of the referring pediatric cardiologist.

\section{Statistics}

Results for the continuous variables are presented as median and range; proportions are expressed with $95 \%$ confidence intervals, with continuity correction for the upper and lower limits of the latter.

\section{Results}

The surgical characteristics of the patients, the anatomy of the septum, the procedures performed, and the discharge echocardiographic findings are given in Table 1. Median aortic crossclamp time was 100 minutes (range 39-180 minutes); median CPB time was 170 minutes (68-269 minutes). A total of $33 \mathrm{VSDs}$ were diagnosed preoperatively and intraoperatively; of these, 7 were apical. Five VSDs were closed with conventional patches and interrupted pledgetsupported sutures, 3 were closed directly, and 6 were left open. Nineteen devices were used, 5 in the apical septum. One patient had 3 , another 4 patients had 2 , and 1 patient had none, because the VSD was recognized but not adequately pinpointed. Six small right apical ventriculotomies were used and closed directly. There were no in-hospital deaths and no deaths during a total of 279 patient-months of follow-up (median 16 months, range 7-41 months). Two patients (cases 5 and 12) had arterial switch and multiple VSD closure. They required pulmonary arterial banding for residual shunting outside the area of the devices. In case 5, the residual VSD was successfully closed percutaneously with an Amplatzer device 6 months later, followed by debanding 3 days after that. Patient 5 also had simultaneous resection of $\mathrm{LV}$ outflow tract obstruction and required pacemaker implantation. He subsequently recovered sinus rhythm. In patient 12, the residual VSD was closed 11 months postoperatively through a standard approach and the pulmonary artery was repaired. Patient 14 had a hypoplastic aortic arch repaired in the neonatal period. Multiple apical muscular VSDs required closure 2 weeks later. During the operation, multiple trabecular VSDs were demonstrated and required two additional crossclamp applications to achieve septation. Cardiac arrest occurred 18 hours postoperatively, and extracorporeal membrane oxygenation was instituted. Weaning from the assist device occurred on day 9. A complete AV block required pacemaker implantation. Two months postoperatively, there was no shunt, and ventricular function was good with normal conduction. Patient 1 has shown progressive development of dilated cardiomyopathy, and eventually typical 


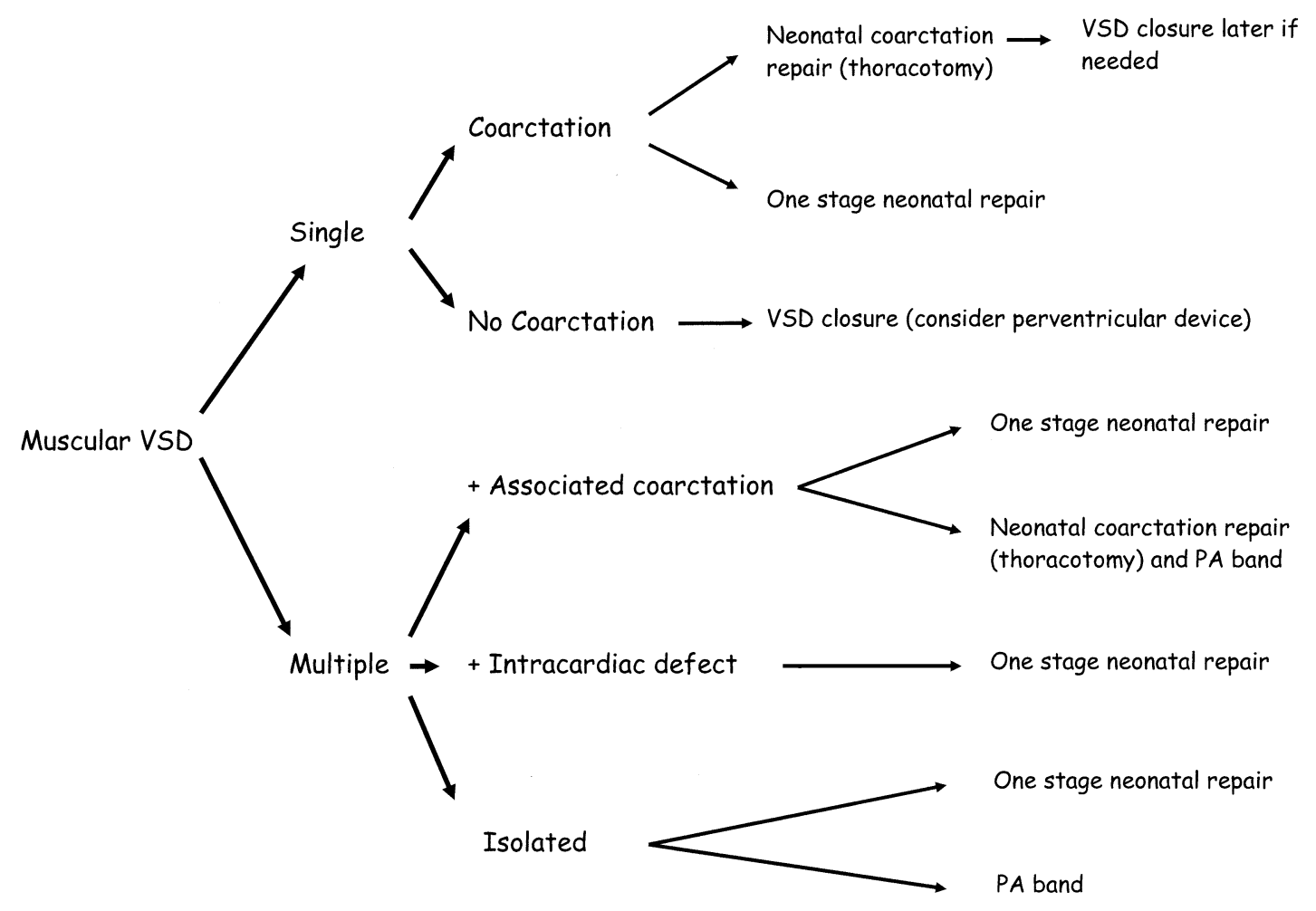

Figure 4. Decision tree for surgical treatment of muscular VSD. PA, Pulmonary artery.

noncompacted LV was diagnosed. All other patients are well and free of cardiac medications. In all 14 patients, there is no evidence of significant left-to-right shunt at latest echocardiographic study.

\section{Discussion}

With conventional techniques, the complications of this surgery are mostly significant residual shunts, need for multiple reoperations, and severe LV dysfunction. High mortality risks are quoted. There are several aspects adding to the difficulties in the management of multiple muscular VSDs.

In the neonate and young infant, VSDs can be difficult or impossible to identify intraoperatively. Through the tricuspid valve, in the search for the VSD, extensive division of muscular trabeculations and bands, including the moderator band, may be performed. These divisions compromise RV function substantially. A small apical RV incision, precisely targeted, can be valuable. It allows fast, accurate, and safe placement of the patch. This emphasizes the necessity to know exactly where the VSDs are. Alternately, several incisions in the quest of the VSDs, together with their closure, if extensive or ill placed, could cause considerable damage. The surgical exposition gained through left ventriculotomies can be disappointing. The leftward aspect of the septum is not free of trabeculations and may be heavily trabeculated at the apex. Moreover, left ventriculotomies are considered by some to be associated with unacceptable long-term risks, including aneurysm formation, LV dysfunction, and ventricular arrhythmia.,

For most teams, catheter-delivered devices are not recommended in this age group. The stiffness of the guide wire but especially of the sheath is responsible for rupture of the mitral valve, tearing of the septum, severe dysrhythmia, and cardiac arrest during the procedure.

Initial palliation with a pulmonary artery band has inherent morbidity and mortality and requires two stages. The added complexity during the second stage includes pericardial adhesions, need for pulmonary artery repair, damage to the potential neoaortic valve, and RV hypertrophy contributing to the difficult location and closure of the VSDs. ${ }^{1-3}$ In many of our neonatal patients, a simple palliation would have been ill advised because of the potential for damage to the pulmonary valve in the nonrepaired transposition or for damage to the conduit in a repaired truncus arteriosus.

Often, undiagnosed additional small VSDs without detectable shunting in the presence of a larger VSD may be unmasked after repair and contribute to a significant residual left-to-right shunt. The technique presented here deals with these issues.

In our series, the technical difficulties were of five types: 
1. The size of the probe did not allow simple apical 4-chamber views without significant disruption of the ventricular geometry. Only transverse cuts and longitudinal view could be obtained with the heart in the pericardial cavity. We prefer epicardial echocardiographic study, because transesophageal probes give poor views of the apex and in our experience have not been useful for apical VSD location. More importantly, we consider the direct handling of the epicardial probe by the operator in itself useful for the location of VSDs. Under CPB, it is easier and more informative because the VSD shunting is increased. The lowering of the temperature slows the heart rate. The heart can be distended gently with the modulation of the venous drainage and can be manipulated safely.

2. Even when adequately located, the main VSD channel can be difficult to transfix.

3. In 2 cases the initial appreciation of the size of the VSD was inadequate, resulting in the insertion of undersized patches. In both cases this had to be corrected with another application of the crossclamp and replacement of the patches with larger ones.

4. Some muscular VSDs are only visible or hemodynamically significant after closure of the other VSDs (patients 7 and 11).

5. Crossclamp times have been long, but these were in relation to complex associated lesions. Each individual double-patch device placement was fast, and the procedure can be done in 10 to 15 minutes. Placement of multiple devices does take time. Patient 14, who had considerable morbidity, needed three crossclamp applications but had a cumulative crossclamp time of 73 minutes. This emphasizes the need for safe and reliable myocardial protection.

Despite these practical limitations, the technique was used in 9 neonates and young infants weighing 2800 to $4100 \mathrm{~g}, 7$ of whom underwent simultaneous complex cardiac repair. No LV incisions were used, and the apical $\mathrm{RV}$ incisions when required have been minimal. If the 2 patients with intraoperative banding are set aside, there was evidence of residual left-to-right shunting detected at postoperative studies in 6 patients. These shunts were not considered of significant magnitude. Two patients had postoperative catheter studies. The pulmonary to systemic perfusion ratios were 1.6:1 and 1:1. The only child with symptoms (patient 1) was slightly exercise limited but has evidence of severe dilated cardiomyopathy most likely not related to the surgical procedure (crossclamp time 45 minutes). Generally, the tiny shunts have tended to subside further with continuing follow-up.

Several surgical managements of multiple VSDs have been described. Kitagawa and colleagues ${ }^{1}$ used different techniques in 33 patients, one of which relies on the concept of an oversized patch placed on the LV side of the septum. Sutures were placed circumferentially through the patch and the rim of the VSD from the LV side. Obviously, this method requires adequate localization and visualization of the VSD during aortic crossclamping and numerous sutures to be brought out from the LV, properly organized and tied. Five patients $(15 \%)$ required reinterventions for residual VSD; early mortality was $3 \%$. In $29 \%$, a left ventriculotomy was used, without, however, evidence of LV dysfunction at midterm follow-up. Kapoor and associates ${ }^{6}$ used a simplified sandwich patch closure in 5 patients. They used a right-angled instrument to probe the septum from the LV side, depending on the presence of a sizeable perimembranous VSD for introduction of the instrument. No follow-up data were given, and the patients were significantly older. Recently, Ootaki and collaborators ${ }^{7}$ presented a series of 11 patients treated with a similar technique, sandwiching the septum between two felt patches. A total of 25 VSDs were present, and 15 were closed with the sandwich technique. The mean age was greater than in our series, and 9 of the 11 had primary palliation. Morbidity was not reported. Their report adds credit to the safety of the method. For both of these reports, however, the main difference from the technique described in this report is the absence of epicardial echocardiography and means of precise location of the VSD before ischemic arrest. We found that even in the few instances in which none of the VSDs were transfixed, having spent sufficient time trying to localize the VSD and using all benchmarks available (trabeculae septomarginalis, tricuspid annulus, aortic valve, acute angle of the anterior septum with the anterior free wall of the RV, direction of the probe), as well as using the guide wire inserted in front of the RV main orifice of the VSD was extremely helpful in the location. Probing the septum with instruments, especially in neonates' and infants' hearts, can be misleading and create communications where they do not exist. Macé and colleagues, ${ }^{8}$ as well as Black and coworkers, ${ }^{9}$ obliterate the VSDs by extensive patching of the RV side of the septum with a single ${ }^{8}$ or several $^{9}$ patches. Operative and follow-up mortalities were zero in both series, and no reinterventions for residual shunts were required. Neither group reported experience with their technique in neonates. Macé found septal motional abnormalities in all patients. In that respect, we believe that our approach with two or more separate devices rather than one very large device better preserves the function of the septum.

Intraoperative placement of occluding devices designed to be delivered percutaneously has been achieved experimentally ${ }^{10}$ and clinically. ${ }^{11,12}$ In a series of 10 animals, muscular and perimembranous VSDs were closed under epicardial echocardiographic guidance, without $\mathrm{CPB} .{ }^{10}$ This study inspired the development of the surgical strategy described here. On follow-up, all muscular VSDs and 60\% 
of perimembranous VSDs remained closed, at the expense of aortic regurgitation in 1 animal. Since our current series was completed, we ourselves have used this approach successfully in 4 patients with isolated single midmuscular VSD.

In their seminal study, Fishberger and associates ${ }^{11}$ attempted to seal the VSD with catheter-bore occluding devices placed intraoperatively with $\mathrm{CPB}$ and crossclamping. Eight patients had complex lesions; 2 had isolated multiple VSDs. The 2 patients with isolated VSDs required reinterventions, and the overall mortality was 50\%. A more recent experience from Toronto ${ }^{12}$ quoted an early mortality of $14 \%$ in 14 patients. The overall mortality (including 1 late heart transplant) was $28 \%$, and the reoperation rate was $21 \%$. The concept of VSD closure with devices designed for catheter delivery but intraoperatively and with CPB is challenged by the present series. It has little advantage in terms of simplicity and crossclamp time. The clinical results are not convincing. It also carries substantial equipment costs. The patches used in this series are inexpensive. They are 2-layered, with a softer PTFE component on the septal side, effectively molding around the VSD, and a stiffer Dacron polyester fabric component on the ventricular side, providing strength and allowing incorporation into the endocardium.

Larger studies focusing on outcome ${ }^{2,3}$ have reported reoperations for residual VSDs in $6 \%$ to $13 \%$, and in one series there was a $7.7 \%$ 30-day mortality. ${ }^{3}$ Importantly, several studies ${ }^{1-3}$ emphasize the merits of primary surgical repair.

In their proposition to treat coarctation complex in neonates with absorbable pulmonary artery band applied at the time of the coarctation repair, Bonnet and associates ${ }^{13}$ spared VSD closure altogether in 10 of 11 patients. Retrospectively, it is interesting to note that the only patient who had severe morbidity in our series (patient 14) belongs to this group of coarctation complex and would most likely have benefited from this alternative technique. Again, since this current series was completed, we ourselves have used absorbable bands in 3 selected patients.

A decision tree was designed to integrate this series into the general approach to the treatment of muscular VSDs in our unit (Figure 4).

\section{Limitations}

The limitations are those of any small, observational, retrospective study. Therefore no statistically founded inferences can be made at this point, and caution should be exercised in any comparisons. However, the main objective was to evaluate safety and feasibility of a novel management strategy. Notably, it is founded on well-established clinical techniques and equipment.

\section{Conclusion}

We believe this technique is a simple, safe, effective, costconscious, and reproducible means of dealing with multiple muscular VSDs in a wide range of settings, in particular complex neonatal cases. In our early experience there have been no deaths. Only in 2 instances was there inability to locate a target VSD, and eventually all patients were fully septated. This method may prove especially valuable in complex cases in which there is a need to avoid timeconsuming procedures while aiming for primary repair of VSDs in infancy.

\section{References}

1. Kitagawa T, Durham LA, Mosca RS, Bove EL. Techniques and results in the management of multiple ventricular septal defects. $J$ Thorac Cardiovasc Surg. 1998;115:848-56.

2. Seddio F, Reddy MV, McElhinney DB, Tworetzky W, Silverman NH, Hanley FL. Multiple ventricular septal defects: how and when should they be repaired? J Thorac Cardiovasc Surg. 1999;117:134-40.

3. Serraf A, Lacour-Gayet F, Bruniaux J, Ouaknine R, Losay J, Petit J, et al. Surgical management of isolated multiple ventricular septal defects: logical approach in 130 cases. J Thorac Cardiovasc Surg. 1992;103: 437-43.

4. Hanna B, Colan SD, Bridges ND, Mayer JE, Castaneda A. Clinical and myocardial status after left ventriculotomy for ventricular septal defect closure. J Am Coll Cardiol. 1991;17:110A.

5. Wollenek G, Wyse R, Sullivan I, Elliott M, de Leval M, Stark J. Closure of muscular ventricular septal defects through a left ventriculotomy. Eur J Cardiothorac Surg. 1996;10:595-8.

6. Kapoor L, Gan MD, Das MB, Mukhopadhyay S, Bandhopadhyay A. Technique to repair multiple muscular ventricular septal defects. J Thorac Cardiovasc Surg. 1999;117:402-3.

7. Ootaki Y, Yamaguchi M, Yoshimura N, Oka S, Yoshida M, Hasegawa T. Surgical management of trabecular ventricular septal defects: the sandwich technique. J Thorac Cardiovasc Surg. 2003;125:508-12.

8. Macé L, Dervanian P, Le Bret E, Folliguet TA, Lambert V, Losay J, et al. "Swiss cheese" septal defects: surgical closure using a single patch with intermediate fixings. Ann Thorac Surg. 1999;67:1754-9.

9. Black MD, Shukla V, Rao V, Smallhorn JF, Freedom RM. Repair of isolated multiple muscular ventricular septal defects: the septal obliteration technique. Ann Thorac Surg. 2000;70:106-10.

10. Amin Z, Gu X, Berry JM, Titus JL, Gidding SS, Rocchini AP. Perventricular closure of ventricular septal defects without cardiopulmonary bypass. Ann Thorac Surg. 1999;68:149-54.

11. Fishberger SB, Bridges ND, Keane JF, Hanley FL, Jonas RA, Mayer JE, et al. Intraoperative device closure of ventricular septal defects. Circulation. 1993;88(Suppl):II205-9.

12. Okubo M, Benson LN, Nykanen D, Azakie A, Van Arsdell G, Coles $\mathrm{J}$, et al. Outcomes of intraoperative device closure of muscular ventricular septal defects. Ann Thorac Surg. 2001;72:416-23.

13. Bonnet D, Patkaï J, Tamisier D, Kachaner J, Vouhé P, Sidi D. A new strategy for the surgical treatment of aortic coarctation associated with ventricular septal defect in infants using an absorbable pulmonary artery band. J Am Coll Cardiol. 1999;34:866-70.

\section{Discussion}

Dr Brizard. We have learned from Dr Bove's articles and experience.

First, I would like to acknowledge the other teams that have used this technique before us, namely the sandwiching of the septum, and also to acknowledge the team in Chicago, who triggered the idea of perforating the RV and pinpointing the VSD with a guide wire. That was experimental work several years ago. 
The first question was related to which patients we consider suitable for a pulmonary artery banding.

The coarctation complex represents a group of patients in whom the balance between the risk of complete closure in the neonatal period and pulmonary artery banding have to be carefully weighed. It is quite often that you can see these patients having closure of their VSDs as an effect of a pulmonary artery band.

The team in Paris has reported the usage of an absorbable band, and in 10 out of 11 patients they managed to see the spontaneous closure under the effect of banding and without the need for reoperation. In a group of patients with coarctation complex, this strategy has to be carefully weighed.

The second question was whether the patches were too small, and how to evaluate the size of the patch.

We have tried not to use too big patches, not to plaster the septum completely. So initially we tried to use just the minimal size patches, just over the size of the VSD as demonstrated on echocardiography. But the size demonstrated on echocardiography is not reliable at all, and we found that on 2 occasions the patches were significantly undersized and were joined together on the control echocardiography and were not appropriately stabilized. On which occasion do we use more than one patch? If the VSDs are far apart at the time of the preoperative echocardiography, we use two patches.

I don't have the figures well in mind at present, but I think on 2 occasions we had to replace the band. On 1 occasion we had to replace the crossclamp and to close an additional VSD that was not diagnosed at the time of the preoperative echocardiography.

Now as to the apical VSD, what we call an apical VSD is not just any that is lower than the moderated band. Some of these VSDs are still accessible from the tricuspid valve. We really call the apical VSD those that are only accessible from the apex of the RV.

I agree that sometimes when the apex of the LV is forming the apex, a left ventriculotomy, or differently speaking a strictly apical ventriculotomy but in fact inside the LV, may be more appropriate. Often in these patients there is almost no left anterior descending coronary artery at this site, and it doesn't make much difference in fact.

Dr Olsson. I would just like to clarify one thing from Dr Bove's comment.

Of the 2 patients mentioned here as having failures, in only 1 instance was it actually a failure to localize the VSD in a neonate with a transposition. The other case had two patches to close, two areas of the shunting; then, after removal from CPB, echocardiography demonstrated a third area that had by then been unmasked. In that situation, it was decided not to go back and crossclamp again to address that area, because it was a complex switch operation, and pulmonary arterial banding was chosen in that case.

Dr Zahid Amin (Omaha, Neb). The technique of advancing the wire under echocardiographic guidance through the RV free wall was introduced by us about 5 years ago while I was in Chicago, and we demonstrated that it was feasible to use in animals and then in human beings.

The only difference between your technique and our technique is that we did not place the patient on CPB at all. We used the wire to advance a sheath over the wire and then used a self-expandable late model device to close the VSDs. I call this technique "perventricular closure of VSDs." We have extended this technique even to perimembranous VSDs. I believe that the most important feature of this technique is avoidance of CPB, which helps to decrease the morbidity and hospital stay. These factors decrease overall hospital costs. It is also easy to recognize any residual VSDs after closure by echocardiography because the heart is beating.

Is it possible that you could use your patch technique through a catheter and avoid CPB, or would you consider using the device, which will save the patient from CPB?

Dr Olsson. If I may just speculate, I think most patches can be delivered through catheters in some way or another. I'm not sure which ones. But I think the important point is that we had 11 patients here with complex lesions who would have been subjected to $\mathrm{CPB}$ anyway; there were only 3 patients with isolated multiple VSDs.

Dr Amin. The data we have are also combined data with single muscular VSD and multiple muscular VSDs with weights as low as $2.9 \mathrm{~kg}$. So these cases were really complicated too, and we used the device.

Dr Olsson. Yes, I was only referring to those cases of transposition.

Dr Brizard. If I may comment, I don't think those devices can be introduced into a catheter or delivery sheath. One of the advantages is obviously the cost. The specially designed devices, like the Amplatzer device, are much more appropriate for the delivery through a catheter sheath.

And your technique in which it is delivered through the RV free wall is extremely appropriate for a single muscular VSD in a neonate, where the major danger of the procedure is actually introducing the guide wire from the femoral artery into the heart.

The stiffness of the guidewire and the sheath, going actually through the RV free wall, allows you to bypass the danger of the catheter delivery in neonates. The advantages of our technique is that we address patients that have complex defects as well and that we have a lower cost.

Dr Carlos Troconis (Caracas, Venezuela). I would like to ask Dr Olsson to comment on a technique we have used lately on such cases, which is the introduction of a small-diameter cardioscope through either the RV or the aortic valve to inspect the LV, identify the holes, and perhaps use your patch to close them.

Dr Olsson. Yes, I've seen that technique reported by Masse and colleagues in which they introduced the cardioscope through the aorta to inspect the LV. It is an elegant technique, and I'm sure it could be useful in selected cases, but we have not seen a definitive need of it.

The learning curve of performing epicardial echocardiography is not that steep. You can master it pretty quickly, and once you have done that, I think it's no longer useful to use another technique.

Dr Emile A. Bacha (Chicago, Ill). We now have a series of 6 patients in whom we've used the technique of periventricular VSD closure with a free wall perforation and crossing the VSD with a wire, with the Amplatzer device, and I think that it is similar to your technique.

The biggest difference is that you don't have to crossclamp and arrest the heart. A lot of our patients also have complex anomalies 
that require $\mathrm{CPB}$, but the advantage is saving yourself 45 minutes of crossclamp time and being able to check-we use transesophageal echocardiography and not epicardial real-time cardiography-whether you have closed the VSD or not before embarking on the repair of the other lesions.

I have a technical question for you. In the patients who have had pulmonary arterial bands with thick trabeculations in the RV apex, did you find it hard to anchor your patch? This is the group of patients in which we found it hard to expand the RV disk, because there simply isn't enough space in the RV apex to place these devices.

Dr Olsson. I agree with the issue of CPB.

Regarding the patch, there may be some RV hypertrophy after the banding, but we haven't had that as a severe problem.

The patch is composed of two layers, and the septal layer is composed of thick PTFE felt, which is soft and sort of molded around the VSD, and an outer layer of knit Dacron polyester fabric, which is stiffer to prevent the patch from becoming funnelshaped when tied down.

Dr Brizard. I have no comment, but I would like to say that we did acknowledge the team of Chicago and their work and their contributions of the generation of the idea.

Dr Thomas L. Spray (Philadelphia, $\mathrm{Pa}$ ). Two patients had heart block, which is 15\%; however, most of the VSDs weren't in the region of the conduction tissue, and you don't sew anything. How does that happen?

Dr Brizard. It is mentioned in the article that we find it disturbing. One of these patients is now in permanent sinus rhythm. It was a case of complex transposition with LV outflow tract obstruction; we did the permanent VSD closure and a resection of the LV outflow tract obstruction. So there are multiple reasons for that patient to have a transient heart block.

The second patient had a complex septum with which I had serious difficulties and that required three crossclamps. This patient had had a cardiac arrest at 18 postoperative hours. He was resuscitated and put on extracorporeal membrane oxygenation. He was in second-degree heart block immediately after the operation, and complete heart block only developed during the resuscitation. He has remained in complete heart block since. I have no explanation.

\begin{abstract}
Online-www.aats.org
Now you can get The Journal of Thoracic and Cardiovascular Surgery online. The Journal online brings you faster delivery time, easy searching of current and back issues, links to PubMed, AATS, WTSA, and other important sites, and more. Visit the Journal online today.
\end{abstract}

\title{
Receive tables of contents by e-mail
}

To receive the tables of contents by e-mail, sign up through our Web site at http://www.mosby.com/jtcvs

Choose E-mail Notification

Simply type your e-mail address in the box and click the Subscribe button.

Alternatively, you may send an e-mail message to majordomo@mosby.com.

Leave the subject line blank and type the following as the body of your message: subscribe jtcvs_toc

You will receive an e-mail to confirm that you have been added to the mailing

list.

Note that TOC e-mails will be sent out when a new issue is posted to the Web site. 